\title{
Caixas para o transporte interno e armazenamento da goiaba 'Paluma' com injúria de impacto
}

\section{Boxes for internal transport and storage of guava 'Paluma' injury with impact}

\author{
Helton S. Silva ${ }^{1}$; Inácia dos Santos Moreira ${ }^{2}$; Tádria C. S. Furtunato ${ }^{3}$, Railene H. C. Rocha ${ }^{4 *}$,Francisco D. A. Sousa
}

\begin{abstract}
Resumo - O objetivo deste trabalho foi avaliar o efeito de diferentes embalagens indicadas para o transporte interno e armazenamento da goiaba 'Paluma' sob a qualidade dos frutos com injúria de impacto. Utilizou-se o delineamento inteiramente casualizado em esquema de parcelas subdivididas no tempo, com quatro repetições e dois frutos por unidade experimental. Os tratamentos forma: $\mathrm{T}_{1}$, testemunha; $\mathrm{T}_{2}$, frutos submetidos a impacto, embalagem em caixa de polietileno; $\mathrm{T}_{3}$, frutos sem impacto, embalagem em caixa de polietileno; $\mathrm{T}_{4}$, frutos submetidos a impacto, embalagem em caixa de papelão; $\mathrm{T}_{5}$, frutos sem impacto, embalagem em caixa de papelão. Não há diferença na qualidade da goiaba 'Paluma' quando transportada ou armazenada em caixas de papelão ou de plástico do tipo polietileno. As goiabas tiveram qualidade adequada para comercialização até o terceiro dia de armazenamento. Ao final do armazenamento observou-se presença de estruturas fúngicas e maior perda de massa nos frutos com injuria de impacto.
\end{abstract}

Palavras-chaves: Psidium guajava, dano mecânico, embalagem

\begin{abstract}
The aim of this study was evaluate the effect of different packages suitable for internal transport and storage of guava 'Paluma' in fruit quality with impact injury. Was used a completely randomized design in a split-plot in time, with four replications and two fruits per experimental unit. Treatments way: T1, control; T2, fruits subjected to impact, polyethylene packaging box, T3, fruit without impact, polyethylene packaging box; T4, fruits subjected to impact, packing in carton; T5, fruit without impact, in carton packaging. There is no difference in the quality of guava 'Paluma' when transported or stored in cardboard boxes or plastic like polyethylene. Guavas had sufficient quality to marketing until the third day of storage. At the end of the storage observed presence of fungal structures and greater weight loss in fruits with injury by impact.
\end{abstract}

Key words: Psidium guajava, packaging, mechanical damage

\footnotetext{
*Autor para correspondência

Recebido para publicação em 02/02/2015; aprovado em 25/02/2015

${ }^{1}$ Engenheiro Agrônomo, Centro de Ciências agrárias, Universidade Federal da Paraíba (CCA/UFPB) Câmpus Areia; (83) 3362-3203. helton@ @ca.ufpb.br

${ }^{2}$ Doutoranda em Engenharia Agrícola, UFCG. inaciamoreira@ymail.com

${ }^{3}$ Mestranda em Horticultura Tropical, UFCG/CCTA tadriacsf@hotmail.com.

${ }^{4}$ Engenheira Agrônoma, Doutora em Fitotecnia, Professora UFCG/CCTA/UAGRA. raileneherica@ @cta.ufcg.edu.br.

${ }^{5}$ Engenheiro Agrônimo, UFCG/CCTA; franciscoufcg@gmail.com
} 


\section{INTRODUÇÃO}

A goiabeira (Psidium guajava, L.) é originária da América Tropical, e no Brasil, encontra-se distribuída naturalmente por todo o território (Souza et al., 2009). Na Paraíba essa espécie é cultivada principalmente por pequenos produtores, sendo de alto valor econômico e social para região. Em 2010 a Paraíba produziu 4.196 t, a quinta maior produção do Nordeste. Ficando atrás dos estados de Pernambuco, Bahia, Ceará e Sergipe que produziram 90.496, 14.217, 9.031 e 4.446 t respectivamente (IBGE, 2012). Grande parte dessa goiaba produzida na Paraíba fica restrita ao mercado local devido à falta de conhecimento técnico e infraestrutura, dos produtores, para ofertar os frutos com o padrão de qualidade necessário para mercados mais distantes.

A carência de cuidados no manuseio da goiaba nas etapas de colheita, transporte e comercialização proporciona injúrias mecânicas que desvalorizam o produto comercialmente. A etapa de transporte dos frutos da propriedade agrícola para o local de comercialização é, provavelmente, a principal fase de ocorrência de injúrias, pois a maioria dos pequenos impactos, compressões e abrasões ocorrem durante o transporte e empilhamento dos frutos, causando manchas que só se tornam visíveis após a maturação (Lichtemberg, 1999).

Alteração na qualidade foram reportadas em vários frutos. Em goiabas 'Paluma', Grigio et al. (2011) constataram que danos por impacto e compressão causou maior perda de massa fresca e redução nos teores de vitamina $\mathrm{C}$, sólidos solúveis e acidez titulável. Em mamões 'Golden', Godoy et al. (2010) observaram que as injúrias por abrasão e impacto promoveram redução da firmeza da polpa e perda de massa. Em pêssego 'Aurora-1', Kasat et al. (2007) reportaram que as injúrias provocadas por corte, compressão e impacto promoveram manchas que comprometeram a aparência dos mesmos. De modo semelhante Durigan et al. (2005) observaram, que as injúrias mecânicas também comprometeram a aparência externa de limas ácidas 'Tahiti' reduzindo a qualidade dos frutos.

A utilização de embalagens inadequadas para o transporte e, principalmente, o excesso de carga nelas acondicionadas aliados ao transporte rodoviário que, muitas vezes é agravado pela má conservação das estradas principais e vicinais das regiões produtoras e o horário cuja temperatura é elevada comprometem seriamente a qualidade final do produto (Castro et al., 2011). De acordo com Sousa et al.(2012) as embalagens a ser usadas, devem evitar alterações das características sensoriais como: sabor, textura, doçura, aceitação global, aroma como também deterioração física, química e microbiológica do produto.

Nesse sentido, objetivou-se avaliar a qualidade de goiaba 'Paluma' quanto ao efeito da injúria por impacto na colheita e diferentes embalagens para o transporte, do campo ao estabelecimento comercial, em Pombal - PB.

\section{MATERIAL E MÉTODOS}

As goiabas foram adquiridas do Instituto Federal da Paraíba (IFPB), São Gonçalo-PB, situado nas seguintes coordenadas geográficas $6^{\circ} 50$ '02,28”S e $38^{\circ} 18^{\prime} 45,05^{\prime}$ O. Os frutos foram colhidos pela manhã, no estado "de dez", que corresponde a cor da casca verde-mate (Pereira, 1995) e, em seguida, conduzidas para o galpão de embalagem do IFPB para aplicação dos tratamentos (T). Utilizou-se o delineamento inteiramente casualizado em esquema de parcelas subdivididas no tempo, com quatro repetições e dois frutos por unidade experimental.

Os tratamentos foram estabelecidos, simulando-se impactos que possam, por ventura, acontecer, na casa de embalagem. Procedeu-se da seguinte forma: $T_{1}$, testemunha, frutos sem injúria mecânica; $\mathrm{T}_{2}$, frutos submetidos a impacto, embalagem em caixa plástica de polietileno; $\mathrm{T}_{3}$, frutos sem impacto, embalagem em caixa plástica de polietileno; $\mathrm{T}_{4}$, frutos submetidos a impacto, embalagem em caixa de papelão; $\mathrm{T}_{5}$, frutos sem impacto, embalagem em caixa de papelão. Após a aplicação dos tratamentos, os frutos foram acondicionados em uma única camada de frutos e protegidos com jornal para evitar o atrito entre frutos na embalagem.

O impacto foi realizado deixando os frutos cair em piso industrial a uma altura de $85 \mathrm{~cm}$. Foram realizado dois impactos em cada fruto, em lados opostos, na região equatorial. Para identificar o local em que o fruto sofreu o impacto, foi posta sob o piso uma etiqueta adesiva que se fixava nos frutos no momento do contato com o piso. Utilizou-se caixas de papelão do tipo telescópica (tampa e fundo) com dimensões externas de 7x20x31cm e a de plástico do tipo polietileno com dimensões externas de 556 x 360 x $311 \mathrm{~mm}$. Os frutos foram transportados para a Universidade Federal de Campina Grande (UFCG) por um percurso de 66 $\mathrm{km}$ em estrada asfaltada e $15 \mathrm{~km}$ de estrada vicinal, no compartimento de carga (no piso da parte traseira) do veiculo, simulando as condições do trajeto percorrido até chegar ao comércio de Pombal - PB.

Ao chegarem, os frutos foram mantidos em sala sob condições ambiente $\left(27^{\circ} \mathrm{C} \pm 2\right.$ e UR $\left.68 \% \pm 5\right)$ e analisados diariamente durante cinco dias, quanto às seguintes características físico-químicas:

a) Perda de massa fresca: Determinada pela diferença entre o peso inicial do fruto e aquele obtido em cada período de avaliação, aferido com auxilio de uma balança digital de precisão, expressa em porcentagem;

b) Cor da epiderme: Determinada de acordo com a escala de cores da Frutiséries (2001) atribuindo-se as notas: 1 Fruto totalmente verde, 2 Verde-claro, 3 Verde-amarelo, 4 Verde-mate e 5 Amarelo;

c) Aparência externa: Avaliada de acordo com a severidade dos defeitos (depressões, manchas e murchas), contidos na casca do fruto, com notas variando de 5 a 0: (5) Frutos com menos de $1 \%$ de defeitos; (4) Frutos com 1 a 10\%; (3) Frutos com 11 a 30\%; (2) Fruto com 31 a 50\%; (1) Fruto com 51 a 60\%; (0) Frutos com mais de 61\% de defeitos;

d) Aparência interna: Avaliada de acordo com a severidade dos defeitos internos (polpa aquosa e mudança de cor dos tecidos), com notas variando de 5 a 0 , considerando as mesmas proporções adotadas nas notas de aparência externa. Sendo considerados impróprios para comercialização os frutos com nota inferior a 3, adaptado de Rocha (2005);

e) Severidade de doenças: Caracterizada pela porcentagem de sintomas de doença e/ou sinais de patógenos em cada fruto. Determinada pela escala de notas que variam de 0 a 4, de acordo com o grau de severidade da doença: (0) frutos sem sintomas de manchas e podridão e sem estruturas fúngicas; (1) frutos com sintomas iniciais (10\%) de podridão e sem estruturas fúngicas; (2) frutos com sintomas de podridão $(20 \%)$ e com estruturas fúngicas; (3) frutos com 
sintomas de podridão (30\%) com estruturas fúngicas; (4) frutos com sintomas de podridão (50\%) com diferentes estruturas fúngicas.

Nas análises subjetivas com atribuições de notas, considerou-se a média de três avaliadores para cada fruto. Para as análises químicas, utilizou-se centrífuga Liquafruits Power marca Mallory (Modelo: 19995-02; Potência: 800 w) para extrair a polpa. Realizaram-se as seguintes análises:

f) Sólidos solúveis (SS): Determinado diretamente na polpa homogeneizada, através de leitura em refratômetro digital (modelo PR - 100, Palette, Atago Co., LTD., Japan) com compensação automática de temperatura. Os resultados foram expressos em \%;

g) Acidez titulável (AT): Determinada em duplicata, utilizando-se $1 \mathrm{~g}$ de polpa, à qual foram completadas para 50 $\mathrm{mL}$ com água destilada e adicionou-se 3 gotas de indicador fenolftaleína alcoólica a 1\%. Em seguida realizou-se a titulação da amostra com solução de $\mathrm{NaOH} \quad 0,1 \mathrm{~N}$, previamente padronizada, expressando-se os resultados em percentagem (\%) de ácido cítrico (AOAC, 1997);

h) $\mathrm{pH}$ : Avaliado diretamente na polpa, com auxílio de um potenciômetro digital marca Tecnopon (Modelo mPA 210P/Versão 7.1);

i) Relação SS/AT: Estabelecida pela razão entre as duas variáveis;

Tabela 1. Perda de massa fresca (\%), em goiaba 'Paluma', com injúria mecânica de impacto e diferentes caixas de embalagens

\begin{tabular}{lllllll}
\hline \multirow{2}{*}{ Tratamentos } & \multicolumn{7}{c}{ Dias de armazenamento $\left(27 \pm 2{ }^{\circ} \mathrm{C}, 68 \pm 5 \% \mathrm{UR}\right)$} \\
\cline { 2 - 7 } & 0 & 1 & 2 & 3 & 4 & 5 \\
\hline T1 & $0,0,0 \mathrm{a}$ & $2,65 \mathrm{a}$ & $4,41 \mathrm{a}$ & $6,34 \mathrm{a}$ & $8,17 \mathrm{~b}$ & $10,44 \mathrm{~b}$ \\
T2 & $0,00 \mathrm{a}$ & $2,61 \mathrm{a}$ & $4,57 \mathrm{a}$ & $6,93 \mathrm{a}$ & $9,18 \mathrm{ab}$ & $11,65 \mathrm{a}$ \\
$\mathrm{T} 3$ & $0,00 \mathrm{a}$ & $2,63 \mathrm{a}$ & $4,47 \mathrm{a}$ & $6,65 \mathrm{a}$ & $8,66 \mathrm{a}$ & $11,05 \mathrm{ab}$ \\
T4 & $0,00 \mathrm{a}$ & $2,78 \mathrm{a}$ & $4,91 \mathrm{a}$ & $7,16 \mathrm{a}$ & $9,31 \mathrm{a}$ & $11,68 \mathrm{a}$ \\
T5 & $0,00 \mathrm{a}$ & $2,69 \mathrm{a}$ & $4,64 \mathrm{a}$ & $6,73 \mathrm{a}$ & $8,76 \mathrm{ab}$ & $11,01 \mathrm{ab}$ \\
\hline CV 1 (Injurias mecânicas) & \multicolumn{7}{c}{$21,04 \%$} \\
\hline \multicolumn{7}{c}{ CV 2 (Armazenamento) } \\
\hline
\end{tabular}

Médias seguidas da mesma letra na coluna, não diferem entre si pelo teste de Tukey ao nível de $5 \%$ probabilidade. $\mathrm{T}_{1}$, testemunha, frutos sem injúria mecânica; $\mathrm{T}_{2}$, frutos submetidos a impacto, embalagem em caixa plástica de polietileno; $\mathrm{T}_{3}$, frutos sem impacto, embalagem em caixa plástica de polietileno; $\mathrm{T}_{4}$, frutos submetidos a impacto, embalagem em caixa de papelão; $\mathrm{T}_{5}$, frutos sem impacto, embalagem em caixa de papelão.

Mudanças na coloração da casca durante o armazenamento da goiaba 'Paluma' revelaram o amadurecimento dos frutos durante o armazenamento, passando de verde-amarelo (4) para totalmente amarelo (5), em todos os tratamentos, porém, não houve diferença quanto à cor entre os tratamentos, na maioria dos tempos de armazenamento avaliados (Tabela 2). Comportamento j) Vitamina C: Avaliada de acordo com metodologia proposta por Strohecker \& Henning (1967), sendo adotada $1 \mathrm{~g}$ de polpa, diluindo-se para $50 \mathrm{~mL}$ de ácido oxálico e posteriormente realizando a titulação com solução de Tilman, determinada em duplicata. Os resultados foram expressos em mg. $100 \mathrm{~g}^{-1}$.

Os dados foram submetidos à análise de variância e teste de comparação de medias (Tukey) ao nível de 5\% de probabilidade utilizando-se o programa SISVAR (Ferreira, 2000).

\section{RESULTADOS E DISCUSSÃO}

Houve maior perda de massa fresca nos frutos com impacto, independente da embalagem utilizada para o transporte (Tabela 1). Nos frutos com impacto registrou-se perda de massa fresca acima de $11,6 \%$ ao final do armazenamento. Valentini et al. (2009) também relataram que caqui 'Rama Forte' com lesão por impacto, a perda de massa fresca, é maior que os frutos sem dano. Entretanto Silva et al. (2011a) constataram que não houve diferença na perda de massa fresca da goiaba 'Paluma' com lesões por impacto, abrasão e corte e a sem dano.

Tabela 2. Cor da casca (notas 1-5) em goiaba 'Paluma', com injúria mecânica de impacto e diferentes caixas de embalagens

\begin{tabular}{lllllll}
\hline \multirow{2}{*}{ Tratamentos } & \multicolumn{7}{c}{ Dias de armazenamento $\left(27 \pm 2{ }^{\circ} \mathrm{C}, 68 \pm 5 \%\right.$ UR $)$} \\
\cline { 2 - 7 } & 0 & 1 & 2 & 3 & 5 \\
\hline T1 & $4,12 \mathrm{a}$ & $4,50 \mathrm{a}$ & $4,87 \mathrm{a}$ & $5,00 \mathrm{a}$ & $5,00 \mathrm{a}$ & $5,00 \mathrm{a}$ \\
$\mathrm{T} 2$ & $4,12 \mathrm{a}$ & $4,50 \mathrm{a}$ & $4,83 \mathrm{a}$ & $4,87 \mathrm{a}$ & $4,91 \mathrm{a}$ & $5,00 \mathrm{a}$ \\
$\mathrm{T} 3$ & $4,12 \mathrm{a}$ & $3,95 \mathrm{ab}$ & $4,74 \mathrm{a}$ & $5,00 \mathrm{a}$ & $5,00 \mathrm{a}$ & $5,00 \mathrm{a}$ \\
T4 & $4,12 \mathrm{a}$ & $4,12 \mathrm{ab}$ & $5,00 \mathrm{a}$ & $5,00 \mathrm{a}$ & $5,00 \mathrm{a}$ & $5,00 \mathrm{a}$ \\
T5 & $4,12 \mathrm{a}$ & $3,87 \mathrm{~b}$ & $4,12 \mathrm{~b}$ & $5,00 \mathrm{a}$ & $5,00 \mathrm{a}$ & $5,00 \mathrm{a}$ \\
\hline CV 1 (Injurias mecânicas) & \multicolumn{7}{c}{$9,25 \%$} \\
\hline CV 2 (Armazenamento)
\end{tabular}

Médias seguidas da mesma letra na coluna, não diferem entre si pelo teste de Tukey ao nível de $5 \%$ probabilidade. $\mathrm{T}_{1}$, testemunha, frutos sem injúria mecânica; $\mathrm{T}_{2}$, frutos submetidos a impacto, embalagem em caixa plástica de polietileno; $\mathrm{T}_{3}$, frutos sem impacto, embalagem em caixa plástica de polietileno; $\mathrm{T}_{4}$, frutos submetidos a impacto, embalagem em caixa de papelão; $\mathrm{T}_{5}$, frutos sem impacto, embalagem em caixa de papelão. 
Houve depreciação na aparência das goiabas ao decorrer do armazenamento em todos os tratamentos. A aparência externa dos frutos permaneceu desejável para comercialização até o $4^{\circ}$ dia de armazenamento, com notas acima de 3, de acordo com Rocha (2005). No ultimo dia de armazenamento apenas os frutos transportados em caixas de papelão e sem dano mecânico $\left(\mathrm{T}_{5}\right)$ foram considerados apropriados para comercialização, o restante teve nota inferior a 3 (Tabela 3), ou seja, com mais de $30 \%$ da casca afetada por depressões, manchas e murcha, sendo considerados impróprios para comercialização segundo Rocha (2005).

Tabela 3. Aparência externa (notas 5-0) em goiaba 'Paluma', com injúria mecânica de impacto e diferentes caixas de embalagens

\begin{tabular}{|c|c|c|c|c|c|c|}
\hline \multirow{2}{*}{ Tratamentos } & \multicolumn{6}{|c|}{ Dias de armazenamento $\left(27 \pm 2{ }^{\circ} \mathrm{C}, 68 \pm 5 \%\right.$ UR $)$} \\
\hline & 0 & 1 & 2 & 3 & 4 & 5 \\
\hline $\mathrm{T} 1$ & 3,91 a & $4,04 a$ & $4,20 \mathrm{a}$ & 4,37 a & $4,00 \mathrm{a}$ & $2,83 a$ \\
\hline $\mathrm{T} 2$ & $3,91 \mathrm{a}$ & $3.75 \mathrm{a}$ & $3.71 \mathrm{a}$ & $3,04 \mathrm{a}$ & $3,08 \mathrm{a}$ & $2,37 \mathrm{a}$ \\
\hline T3 & 3,91 a & $4,58 \mathrm{a}$ & $3,83 \mathrm{a}$ & 3,71 a & $3,50 \mathrm{a}$ & $2,75 \mathrm{a}$ \\
\hline $\mathrm{T} 4$ & $3,91 \mathrm{a}$ & $3,75 \mathrm{a}$ & $3,54 \mathrm{a}$ & $3,83 \mathrm{a}$ & $3,25 \mathrm{a}$ & $2,87 \mathrm{a}$ \\
\hline $\mathrm{T} 5$ & $3,91 \mathrm{a}$ & $4,33 \mathrm{a}$ & $4,29 \mathrm{a}$ & $4,12 \mathrm{a}$ & $3,79 \mathrm{a}$ & $4,75 \mathrm{a}$ \\
\hline \multicolumn{4}{|c|}{ CV 1 (Injurias mecânicas) } & \multicolumn{2}{|c|}{$44,77 \%$} & \\
\hline CV 2 (Armaz & ento) & & & 20 & & \\
\hline
\end{tabular}

Médias seguidas da mesma letra na coluna, não diferem entre si pelo teste de Tukey ao nível de $5 \%$ probabilidade. $\mathrm{T}_{1}$, testemunha, frutos sem injúria mecânica; $\mathrm{T}_{2}$, frutos submetidos a impacto, embalagem em caixa plástica de polietileno; $\mathrm{T}_{3}$, frutos sem impacto, embalagem em caixa plástica de polietileno; $\mathrm{T}_{4}$, frutos submetidos a impacto, embalagem em caixa de papelão; $\mathrm{T}_{5}$, frutos sem impacto, embalagem em caixa de papelão.

Grigio et al.(2011) observaram que frutos quando submetidos a dois tipos de danos simultaneamente, o armazenamento em sacolas de polietileno de baixa densidade não reduzir a velocidade metabólica desses frutos, tornandoos inaptos à comercialização em curto período de tempo. Silva et al. (2013) constataram que goiaba 'Paluma' com lesões de impacto, corte e abrasão ao final do armazenamento de 17 dias, sendo 11 dias refrigerado $\left(10^{\circ} \mathrm{C}\right)$ e 6 dias ambiente $\left(30^{\circ} \mathrm{C}\right)$, foram consideradas impróprias para comercialização, enquanto os frutos sem lesões ainda tinham aparência externa desejável para comercialização.

Para aparência interna até o $3^{\circ}$ dia de armazenamento, a maioria dos frutos recebeu notas superiores a 3 (menos de $30 \%$ de polpa aquosa e mudança de cor dos tecidos), sendo considerados apropriados para comercialização. Já no último dia de armazenamento todos os frutos foram considerados impróprios para comercialização, com notas inferiores a 3 (Tabela 4), correspondendo a mais de $30 \%$ de polpa aquosa com mudança de cor no tecido (Rocha, 2005).

Tabela 4. Aparência interna (notas 5-0) em goiaba 'Paluma', com injúria mecânica de impacto e diferentes caixas de embalagens

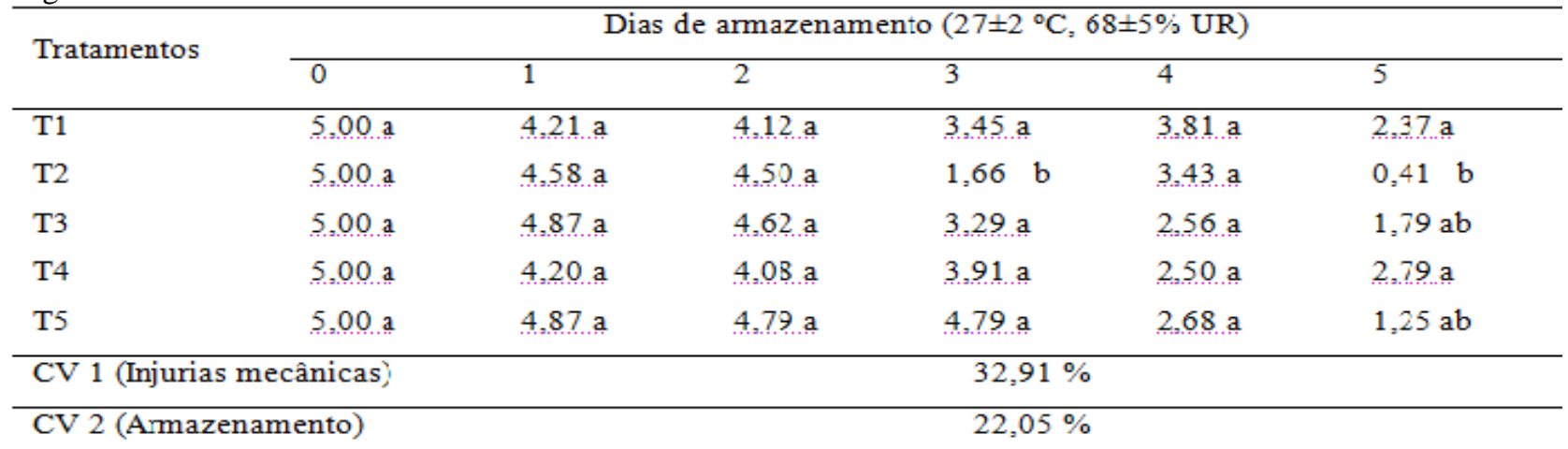

Médias seguidas da mesma letra na coluna, não diferem entre si pelo teste de Tukey ao nível de 5\% probabilidade. $\mathrm{T}_{1}$, testemunha, frutos sem injúria mecânica; $\mathrm{T}_{2}$, frutos submetidos a impacto, embalagem em caixa plástica de polietileno; $\mathrm{T}_{3}$, frutos sem impacto, embalagem em caixa plástica de polietileno; $\mathrm{T}_{4}$, frutos submetidos a impacto, embalagem em caixa de papelão; $\mathrm{T}_{5}$, frutos sem impacto, embalagem em caixa de papelão.

A aparência interna de lima ácida 'Tahiti' foi prejudicada pelos danos por impacto, corte e compressão, sendo consideradas impróprias para comercialização a partir do $9^{\circ}$ dia de armazenamento, enquanto os frutos sem lesões no $15^{\circ}$ dia ainda tinham condições adequadas para comercio (Duringan et al., 2005). Godoy et al. (2010) evidenciaram em mamão 'Golden' com lesão por impacto o colapso interno dos frutos. Silva et al. (2013) também observaram comprometimento da aparência interna de goiaba 'Paluma' com lesão por impacto, corte e abrasão.

Não houve diferença entre os tratamentos para a severidade de doença. No final do armazenamento os frutos tinham estruturas fúngicas e $20 \%$ de sua casca afetada por sintomas de podridão, correspondendo à nota 2 (Tabela 5). 
Tabela 5. Severidade de doença (notas 0-4) em goiaba 'Paluma', submetida à injúria mecânica de impacto e diferentes caixas de embalagens

\begin{tabular}{|c|c|c|c|c|c|c|}
\hline \multirow{2}{*}{ Tratamentos } & \multicolumn{6}{|c|}{ Dias de armazenamento $\left(27 \pm 2{ }^{\circ} \mathrm{C}, 68 \pm 5 \%\right.$ UR) } \\
\hline & 0 & 1 & 2 & 3 & 4 & 5 \\
\hline T1 & 0,82 a & $0,21 \ldots$ & 0,08 a & 0,12 a & 0,70 a & 1,70 a \\
\hline $\mathrm{T} 2$ & 0,82 a & 0,16 a & 0,00 a & 0,83 a & 1,00 a & $2,54, \mathrm{a}$ \\
\hline T3 & 0,82 a & $0,00,0$ a & $0,00, a$ & 0,45 a & 0,54 a & $1,83 \ldots$ \\
\hline $\mathrm{T} 4$ & $0,82 \ldots$ & 0,16 a & 0,16 a & 0,33 a & 1,33 a & 2,00 a \\
\hline T5 & 0,82 a & $0,04 \ldots$ & 0,08 a & 0,00 a & 0,83 a & $1,71 \ldots$ \\
\hline \multicolumn{4}{|c|}{ CV 1 (Injurias mecânicas) } & \multicolumn{3}{|c|}{$119,31 \%$} \\
\hline
\end{tabular}

Médias seguidas da mesma letra na coluna, não diferem entre si pelo teste de Tukey ao nível de $5 \%$ probabilidade. $\mathrm{T}_{1}$, testemunha, frutos sem injúria mecânica; $\mathrm{T}_{2}$, frutos submetidos a impacto, embalagem em caixa plástica de polietileno; $\mathrm{T}_{3}$, frutos sem impacto, embalagem em caixa plástica de polietileno; $\mathrm{T}_{4}$, frutos submetidos a impacto, embalagem em caixa de papelão; $\mathrm{T}_{5}$, frutos sem impacto, embalagem em caixa de papelão.

Steffens et al. (2008) constataram que maçãs submetidas a impacto teve maior incidência de podridões $(28,1 \%)$ quando comparada com os frutos sem danos $(3,3 \%)$, com nove dias após aplicação do dano. Em goiaba 'Paluma' com lesão por impacto, corte e abrasão observou-se que aos 17 dias de armazenamento $\left(11\right.$ dias a $10^{\circ} \mathrm{C}$ e 6 dias a $30^{\circ} \mathrm{C}$ ) os frutos apresentavam alta severidade de doenças, com $30 \%$ da casca do fruto afetada por podridão e com presença de estruturas fúngicas (Silva et al., 2013). Porem Fischer et al.(2011) relatam que as injúrias mecânicas oriundas do manuseio dos frutos na colheita e pós-colheita não influenciaram a incidência de doenças pós-colheita nos frutos de goiaba das cultivares 'Paluma' e 'Pedro Sato'.
Os sólidos solúveis da goiaba 'Paluma' variou entre 8,52 a $11,00 \%$, nos frutos analisados, porém, não houve diferença significativa entre os tratamentos (Tabela 6). Silva et al. (2011b) em trabalho realizado com goiaba 'Paluma' também observaram valores de sólidos solúveis semelhantes ao deste trabalho. No entanto, observou-se que os menores valores de sólidos solúveis foram dos frutos com injuria por impacto quando comparado com a testemunha. Amarante et al.(2013) relatam que frutos de cultivares de goiabeira-serrana não apresentaram influência nos teores de sólidos solúveis quanto a ocorrência de dano mecânico.

Tabela 6. Sólidos solúveis (\%) em goiaba 'Paluma', com injúria mecânica de impacto e diferentes caixas de embalagens

\begin{tabular}{|c|c|c|c|c|c|c|}
\hline \multirow{2}{*}{ Tratamentos } & \multicolumn{6}{|c|}{ Dias de armazenamento $\left(27 \pm 2{ }^{\circ} \mathrm{C}, 68 \pm 5 \%\right.$ UR $)$} \\
\hline & 0 & 1 & 2 & 3 & 4 & 5 \\
\hline T1 & 9,66 a & $10.27 \ldots$ & 9,90 a & 9,30 a & 9,68 a & $10,73, \mathrm{a}$ \\
\hline $\mathrm{T} 2$ & 9,66 a & 9,21 a & $10,16 \ldots$ & 8,52 a & $10,62, \mathrm{a}$ & $11,0 \quad a$ \\
\hline $\mathrm{T} 3$ & 9,66 a & 8,82 a & $10,0,0, \mathrm{a}$ & $10.53 . \mathrm{a}$ & 9,92 a & $10,87 \ldots$ \\
\hline $\mathrm{T} 4$ & 9,66 a & $10,07 \ldots$ & 9,52 a & $10.11 \ldots$ & 9,32 a & 9,97 a \\
\hline T5 & 9,66 a & 10,10 a & 9,83 a & $10,42 \mathrm{a}$ & 10,63 a & $10,02 . a$ \\
\hline
\end{tabular}

\begin{tabular}{ll}
\hline CV 1 (Injurias mecânicas) & $6,24 \%$ \\
\hline CV 2 (Armazenamento) & $10,34 \%$
\end{tabular}

Médias seguidas da mesma letra na coluna, não diferem entre si pelo teste de Tukey ao nível de $5 \%$ probabilidade. $\mathrm{T}_{1}$, testemunha, frutos sem injúria mecânica; $\mathrm{T}_{2}$, frutos submetidos a impacto, embalagem em caixa plástica de polietileno; $\mathrm{T}_{3}$, frutos sem impacto, embalagem em caixa plástica de polietileno; $\mathrm{T}_{4}$, frutos submetidos a impacto, embalagem em caixa de papelão; $\mathrm{T}_{5}$, frutos sem impacto, embalagem em caixa de papelão.

Em caqui 'Rama Forte' e Kiwi 'Bruno' os sólidos solúveis não diferiram entre os tratamentos com e sem dano mecânico (Valentini et al., 2009; Alves et al., 2010). Corroborando com os resultados deste trabalho.

Não houve diferença entre os tratamentos para acidez titulável. A acidez dos frutos permaneceu entre 0,59 a $0,85 \%$ de ácido cítrico (Tabela 7). Alves et al. (2010) constataram que não houve diferença nos valores de acidez titulável entre kiwi 'Bruno' submetido a impacto e o controle. No entanto Silva et al. (2011b) observaram menor acidez em goiabas 'Paluma' com injuria mecânica, quando comparado com os frutos sem injuria. 
Tabela 7. Acidez titulável (\% acido cítrico) em goiaba 'Paluma', com injúria mecânica de impacto e diferentes caixas de embalagens

\begin{tabular}{lllllll}
\hline \multirow{2}{*}{ Tratamentos } & \multicolumn{7}{c}{ Dias de armazenamento $\left(27 \pm 2{ }^{\circ} \mathrm{C}, 68 \pm 5 \%\right.$ UR) } \\
\cline { 2 - 7 } & 0 & 1 & 2 & 3 & 4 \\
\hline T1 & $0,69 \mathrm{a}$ & $0,60 \mathrm{~b}$ & $0,67 \mathrm{a}$ & $0,69 \mathrm{a}$ & $0,68 \mathrm{a}$ & $0,69 \mathrm{a}$ \\
$\mathrm{T} 2$ & $0,69 \mathrm{a}$ & $0,67 \mathrm{ab}$ & $0,69 \mathrm{a}$ & $0,75 \mathrm{a}$ & $0,78 \mathrm{a}$ & $0,63 \mathrm{a}$ \\
$\mathrm{T} 3$ & $0,69 \mathrm{a}$ & $0,74 \mathrm{ab}$ & $0,70 \mathrm{a}$ & $0,68 \mathrm{a}$ & $0,83 \mathrm{a}$ & $0,59 \mathrm{a}$ \\
$\mathrm{T} 4$ & $0,69 \mathrm{a}$ & $0,68 \mathrm{ab}$ & $0,65 \mathrm{a}$ & $0,73 \mathrm{a}$ & $0,80 \mathrm{a}$ & $0,61 \ldots$ \\
$\mathrm{T} 5$ & $0,69 \mathrm{a}$ & $0,84 \mathrm{a}$ & $0,84 \mathrm{a}$ & $0,82 \mathrm{a}$ & $0,85 \mathrm{a}$ & $0,69 \mathrm{a}$ \\
\hline CV 1 (Injurias mecânicas) & \multicolumn{7}{c}{$30,85 \%$} & $14,15 \%$ & \\
\hline CV 2 (Armazenamento)
\end{tabular}

Médias seguidas da mesma letra na coluna, não diferem entre si pelo teste de Tukey ao nível de $5 \%$ probabilidade. $\mathrm{T}_{1}$, testemunha, frutos sem injúria mecânica; $\mathrm{T}_{2}$, frutos submetidos a impacto, embalagem em caixa plástica de polietileno; $\mathrm{T}_{3}$, frutos sem impacto, embalagem em caixa plástica de polietileno; $\mathrm{T}_{4}$, frutos submetidos a impacto, embalagem em caixa de papelão; $\mathrm{T}_{5}$, frutos sem impacto, embalagem em caixa de papelão.

Os valores de pH variaram entre 3,2 e 3,82 (Tabela 8), havendo pouca diferença de nos valores de $\mathrm{pH}$ entre os tratamentos. Valores semelhantes foram relatos por Silva et al. (2011b) em trabalho realizado com goiaba 'Paluma'.
Rocha (2008) também observou que não houve diferença de pH entre os melões Gália 'Solar King' com e sem danos mecânicos.

Tabela 8. pH em goiaba 'Paluma', com injúria mecânica de impacto e diferentes caixas de embalagens

\begin{tabular}{lllllll}
\hline \multirow{2}{*}{ Tratamentos } & \multicolumn{7}{c}{ Dias de armazenamento $\left(27 \pm 2{ }^{\circ} \mathrm{C}, 68 \pm 5 \% \mathrm{UR}\right)$} \\
\cline { 2 - 7 } & 0 & 1 & 2 & 3 & 4 \\
\hline T1 & $3,51 . \mathrm{a}$ & $3,52 \mathrm{a}$ & $3,54 \mathrm{a}$ & $3,43 \mathrm{ab}$ & $3,53 \mathrm{~cd}$ & $3,41 \mathrm{a}$ \\
$\mathrm{T} 2$ & $3,51 \mathrm{a}$ & $3,54 \mathrm{a}$ & $3,44 \mathrm{a}$ & $3,48 \mathrm{a}$ & $3,44 \mathrm{a}$ & $3,42 \mathrm{a}$ \\
$\mathrm{T} 3$ & $3,51 \mathrm{a}$ & $3,59 \mathrm{a}$ & $3,49 \mathrm{a}$ & $3,28 \mathrm{~b}$ & $3,71 \mathrm{ab}$ & $3,38 \mathrm{a}$ \\
$\mathrm{T} 4$ & $3,51 \mathrm{a}$ & $3,62 \mathrm{a}$ & $3,48 \mathrm{a}$ & $3,30 \mathrm{~b}$ & $3,82 \mathrm{a}$ & $3,49, \mathrm{a}$ \\
T5 & $3,51 \mathrm{a}$ & $3,60 \mathrm{a}$ & $3,42 \mathrm{a}$ & $3,33 \mathrm{ab}$ & $3,63 \mathrm{bc}$ & $3,47 \mathrm{a}$ \\
\hline CV 1 (Injurias mecânicas) & \multicolumn{7}{c}{$3,31 \%$} \\
\hline CV 2 (Armazenamento)
\end{tabular}

Médias seguidas da mesma letra na coluna, não diferem entre si pelo teste de Tukey ao nível de $5 \%$ probabilidade. $\mathrm{T}_{1}$, testemunha, frutos sem injúria mecânica; $T_{2}$, frutos submetidos a impacto, embalagem em caixa plástica de polietileno; $T_{3}$, frutos sem impacto, embalagem em caixa plástica de polietileno; $T_{4}$, frutos submetidos a impacto, embalagem em caixa de papelão; $T_{5}$, frutos sem impacto, embalagem em caixa de papelão.

Verificou-se pouca variação na relação SS/AT das 16,34, 14,89 para $T_{1}, T_{2}, T_{3}, T_{4}, T_{5}$, respectivamente (Tabela goiabas, ao final do armazenamento foi registrado os seguintes valores de relação SS/AT $16,12,17,30,18,83$,

Tabela 9. Relação SS/AT em goiaba 'Paluma', com injúria mecânica de impacto e diferentes caixas de embalagens

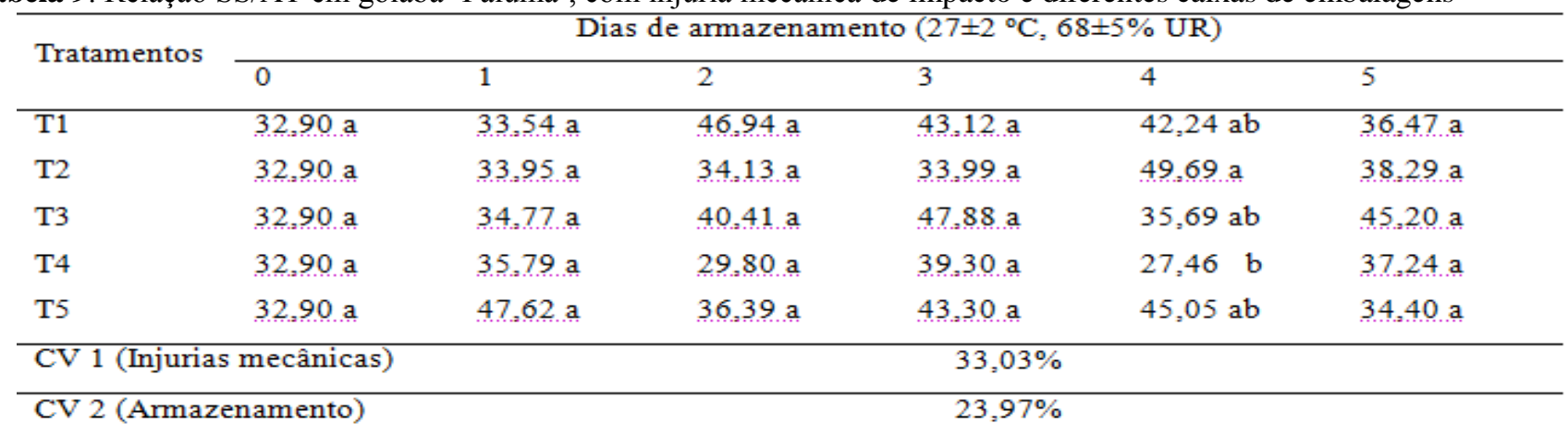

Médias seguidas da mesma letra na coluna, não diferem entre si pelo teste de Tukey ao nível de $5 \%$ probabilidade. $\mathrm{T}_{1}$, testemunha, frutos sem injúria mecânica; $\mathrm{T}_{2}$, frutos submetidos a impacto, embalagem em caixa plástica de polietileno; $\mathrm{T}_{3}$, frutos sem impacto, embalagem em caixa plástica de polietileno; $\mathrm{T}_{4}$, frutos submetidos a impacto, embalagem em caixa de papelão; $\mathrm{T}_{5}$, frutos sem impacto, embalagem em caixa de papelão.

Em trabalho realizado com goiaba 'Paluma' constatouse que não houve diferença de SS/AT entre os frutos com e sem injúrias mecânicas (Silva et al., 2011b). De forma semelhante, Durigan et al. (2005) não verificaram diferença na relação SS/AT em limas acida 'Tahiti' submetidas a impacto, compressão e corte quando comparadas com os frutos sem injúrias mecânicas. Já, Aguila et al. (2010) constataram que ocorreu aumento no SS/AT durante o 
armazenamento (21 dias a $25^{\circ} \mathrm{C}$ e $75 \%$ HR) de banana 'Nanicão' submetida a diferentes injúrias mecânicas, com os menores valores ao final do armazenamento para os frutos submetidos a impacto.

Não houve diferença na vitamina $\mathrm{C}$ entre os tratamentos, registrando-se valores entre 27,46 a $49,69 \mathrm{mg} \cdot 100^{-1} \mathrm{~g}$ (Tabela 10). Silva et al. (2011b) observaram teores de vitamina $C$ entre 41,66 e 76,12 mg. $100^{-1} \mathrm{~g}$, em goiaba 'Paluma'. Os mesmos autores reportaram menor vitamina $\mathrm{C}$ nos frutos com injuria por impacto, quando comparado com os frutos sem dano (SILVA et al. 2011b). Grigio et al. (2011) verificaram em goiaba 'Paluma' submetidos a impacto e compressão declínio mais rápido na vitamina $\mathrm{C}$ quando comparado com os frutos sem injúrias mecânicas.

Tabela 10. Vitamina C (mg $\left.100^{-1} \mathrm{~g}\right)$ em goiaba 'Paluma', com injúria mecânica de impacto e diferentes caixas de embalagens

\begin{tabular}{|c|c|c|c|c|c|c|}
\hline \multirow{2}{*}{ Tratamentos } & \multicolumn{6}{|c|}{ Dias de armazenamento $\left(27 \pm 2{ }^{\circ} \mathrm{C}, 68 \pm 5 \%\right.$ UR $)$} \\
\hline & 0 & 1 & 2 & 3 & 4 & 5 \\
\hline T1 & 32,90 a & $33.54 a$ & $46,94 \mathrm{a}$ & $43.12 \mathrm{a}$ & $42,24 \mathrm{ab}$ & $36,47 \ldots$ \\
\hline $\mathrm{T} 2$ & $32.90 \mathrm{a}$ & 33.95 a & $34.13 \mathrm{a}$ & 33.99 a & 49.69 a & 38,29 a \\
\hline $\mathrm{T} 3$ & $32.90 \mathrm{a}$ & $34.77 \ldots$ & $40,41 \ldots$ & $47,88 \mathrm{a}$ & $35,69 \mathrm{ab}$ & $45,20 \mathrm{a}$ \\
\hline $\mathrm{T} 4$ & 32.90 a & $3.5 .79 . \mathrm{a}$ & $29.80 . \mathrm{a}$ & $39.30 . \mathrm{a}$ & $27,46 \quad b$ & 37,24 a \\
\hline T5 & $32.90 \mathrm{a}$ & $47,62 \mathrm{a}$ & $36,39 \mathrm{a}$ & $43,30 \mathrm{a}$ & $45,05 \mathrm{ab}$ & $34.40 \mathrm{a}$ \\
\hline CV 1 (Injuria & mecânicas) & & & 33,03 & & \\
\hline
\end{tabular}

Médias seguidas da mesma letra na coluna, não diferem entre si pelo teste de Tukey ao nível de $5 \%$ probabilidade. $\mathrm{T}_{1}$, testemunha, frutos sem injúria mecânica; $\mathrm{T}_{2}$, frutos submetidos a impacto, embalagem em caixa plástica de polietileno; $\mathrm{T}_{3}$, frutos sem impacto, embalagem em caixa plástica de polietileno; $\mathrm{T}_{4}$, frutos submetidos a impacto, embalagem em caixa de papelão; $\mathrm{T}_{5}$, frutos sem impacto, embalagem em caixa de papelão.

\section{CONCLUSÕES}

1. Não houve diferença na qualidade da goiaba 'Paluma' quando transportada ou armazenada em caixas de papelão ou de plástico do tipo polietileno.

2. As goiabas tiveram qualidade adequada para comercialização até o terceiro dia de armazenamento.

3. Ao final do armazenamento observou-se presença de estruturas fúngicas e maior perda de massa nos frutos com injuria por impacto.

\section{REFERÊNCIAS BIBLIOGRÁFICAS}

AGUILA, J. S.; AGUILA, L. S. H; SASAKI, F. F.; TSUMANUMA, G. M.; ONGARELLI, M. G.; SPOTO, M. H. F.; JACOMINO, A. P.; ORTEGA, E. M. M.; KLUGE, R. A. Modificaciones post-cosecha de banana dañada mecánicamente. Revista Iberoamericana de Tecnologia Postcosecha, v.10, p.3-85, 2010.

ALVES, E. O.; STEFFENS, C. A.; AMARANTE, C. V. T.; HENDGES, M. V.; ZANARDI, O. Z.; MIQUELOTO, A.; SILVEIRA, J. P. G.; BRACKMANN, A. Amadurecimento de kiwis 'bruno' submetidos ao dano mecânico de impacto e ao tratamento com 1metilciclopropeno. Bragantia, v.69, p.753-758, 2010.

AMARANTE, C. V. T.; STEFFENS, C. A.; BENINCÁ, T. D. T.; HACKBARTH, C.; SANTOS, K. L. Qualidade e potencial de conservação pós-colheita dos frutos em cultivares brasileiras de goiabeira-serrana. Revista Brasileira de Fruticultura, Jaboticabal - SP, v. 35, n. 4, p. 990-999, Dezembro 2013.

AOAC. Official methods of analysis of the Association of Official Analytical Chemists International. 16. ed. Washington: Patricia Cummiff, 1997.
CASTRO, L. R.; CORTEZ, L. A. B.; JORGE, J. T. Influência da embalagem no desenvolvimento de injúrias mecânicas em tomates. Ciência e Tecnologia de Alimentos, v.21, p.26-33, 2011.

DURIGAN, M. F. B.; MATTIUZ, B-H.; DURIGAN, J. F. Injúrias mecânicas na qualidade pós-colheita de lima ácida 'Tahiti' armazenada sob condição ambiente. Revista Brasileira de Fruticultura, v.27, p.369-372, 2005.

FERREIRA, D. F. Análises estatísticas por meio do Sisvar para Windows versão 4.0. In: Reunião Anual da Região Brasileira da Sociedade internacional de Biometria, 45, 2000, São Carlos. Anais... São Carlos: UFSCar, 2000.

FISCHER, I. H. ALMEIDA; A. M.; ARRUDA, M. C.; BERTANI, R. M. A.; GARCIA, M. J. M .; AMORIM; L. Danos em pós-colheita de goiabas na Região do CentroOeste Paulista. Bragantia, Campinas, v.70, n.3, p. 570576, 2011.

FRUTISÉRIES. Seminário Nacional de Agricultura Irrigada e Desenvolvimento Sustentável. 2001. <http://www.integracao.gov.br/Infraestruturahidrica/ publicacoes/frutiseries.asp>08 Ago 2011.

GODOY, A. E.; JACOMINO, A. P.; PEREIRA, E. C. C.; GUTIERREZ, A. S. D.; VIEIRA, C. E. M.; FORATO, L. A. Injúrias mecânicas e seus efeitos na qualidade de mamões Golden. Revista Brasileira de Fruticultura, v.32, p.682-691, 2010.

GRIGIO, M. L.; NEVES, L. C.; TOSIN, J. M.; NASCIMENTO, C. J.; CHAGAS, E. A.; VIEITES, R. L. Efeito da modificação atmosférica em goiabas var. Paluma na redução de danos mecânicos em pós-colheita. Revista Agroambiente On-line, v.5,p.57-65, 2011. < 
http://revista.ufrr.br/index.php/agroambiente/article/view/ 406.> 14 mar 2015.

IBGE, Instituto Brasileiro de Geografia e Estatística. Produção Agrícola Municipal. <http://www.sidra.ibge.gov.br.> 15 Jan 2012.

KASAT, G. F.; MATTIUZ, B-H.; OGASSAVARA, F. O.; BIANCO, M. S.; MORGADO, C. M. A.; CUNHA JR., L. C. Injúrias mecânicas e seus efeitos em pêssego 'aurora1'. Revista Brasileira de Fruticultura, v.29, p.318-322, 2007.

LICHTEMBERG, L. A. Colheita e pós-colheita de banana. Banana: produção, colheita e pós-colheita. Informe Agropecuário, v.20, p.73-90, 1999.

PEREIRA, F. M. Cultura da goiabeira. 1. ed. Jaboticabal: FUNEP, 1995. 47 p.

ROCHA, R. H. C.; NASCIMENTO, S. R. C.; MENEZES, J. B.; NUNES, G. H. S.; SILVA, E. O. Qualidade póscolheita do mamão formosa armazenado sob refrigeração. Revista Brasileira de Fruticultura, v.27, p.386-389, 2005 .

ROCHA, R. H. C. Alterações anatômicas, físicas e fisiológicas induzidas por estresses mecânicos em melão Gália. Viçosa: UFV, 2008. 149p. Tese de Doutorado.

SILVA, H. S.; ROCHA, R. H.C.; SOUSA, F. A.; OLIVEIRA, M. G. F.; CÉZAR, M. A. Estresses mecânicos em goiaba 'paluma' avaliada durante o armazenamento sob condições de refrigeração e ambiente. In: Simpósio de Ciências d Tecnologia De Alimentos, 3., 2011, Recife, Anais... Recife: UFRPE, 2011a.

SILVA, H. S.; ROCHA, R. H.C.; SOUSA, F. A.; OLIVEIRA, M. G. F.; CÉZAR, M. A. Goiaba 'Paluma' induzida a estresses mecânicos e avaliações químicas e físicas durante o armazenamento. In: Simpósio de Ciências d Tecnologia De Alimentos, 3., 2011, Recife, Anais... Recife: UFRPE, 2011b.

SILVA, H. S.; ROCHA, R. H. C.; SOUSA, F. A. Qualidade de goiabas cv. 'paluma' submetidas a injúrias mecânicas e frigoarmazenamento. Revista Caatinga, v.26, p.49-54, 2013.

SOUZA, H. A.; AMORIM, D. A.; ROZANE, D. E.; NATALE, W. Pesquisas com goiabeira (Psidium guajava L.) no Brasil: breve histórico e perspectivas futuras. In: Natale, W. Rozane, D. E.; Souza, H. A.; Amorim, D. A. (Org.). Cultura da goiaba: do plantio à comercialização. Jaboticabal, 2009. v. 2 p. 28.

SOUSA, L. C. F. S.; SOUSA, J. S.; BORGES, M. G. B.; MACHADO, A. V.; SILVA, M. J. S.; FERREIRA, R. T. F. V.; SALGADO, A. B.; Tecnologia de embalagens e conservação de alimentos quanto aos aspectos físico, químico e microbiológico. Agropecuária Científica no Semiárido. V. 8, n. 1, p. 19-27, jan - mar, 2012.
STEFFENS, C. A.; ESPÍNDOLA, B. P.; AMARANTE, C. V. T.; SILVEIRA, J. P. G.; CHECHI, R.; BRACKMANN, A. Respiração, produção de etileno e qualidade de maçãs "Gala" em função do dano mecânico por impacto e da aplicação de 1-metilciclopropeno. Ciência Rural, v.38, p.1864-1870, 2008.

STROHECKER, R.; HENINING, H. M. Análisis de vitaminas: métodos comprobrados. Madrid: Paz Montalvo. 1967. 42 p.

VALENTINI, S. R. T.; FERREIRA, M. D.; ATARASSI, M. E.; BENATO, E. A. Avaliação de linhas de beneficiamento e impactos de queda na qualidade de caqui "Rama Forte". Engenharia Agrícola, v.29, p.642-655, 2009. 